\section{Children of the (Touch)screen: A Genesis}

Sol B. Gaitán

The Dalton School, New York City
Scholarly and Research

Communication

VOLUME 4 / ISSUE 3 / 2013

\begin{abstract}
This article describes experiments in teaching Spanish and Spanish literature using technology, which began in 1993 and have continued until today. The article describes the exciting genesis of a layperson who was lucky enough to dare, try, assess, and renew her teaching along the way through the use of technology via incipient uses of the Internet.
\end{abstract}

\section{Keywords}

Teaching; Technology

Thousands of words have already been written about the prevalence of social networks in the life of adolescents, the changing reading habits of a world connected to the Internet, the attention deficit that this "brave new world" is producing, and the impact of all of this on learning. However, a world exists beyond the Internet. We live in it and have an impact upon on it. Because I am a teacher who lives in both worlds, I believe in the need to connect the two, using the same tools that students use for pleasure.

The advances of technology in the Digital age have permeated every area of society, from interpersonal communication to the way information is disseminated. Today's children, even toddlers, have an attraction to the screen that was not imagined at the dawn of technology. They manipulate sophisticated software, search the Internet, play

\section{CCSP Press}

Scholarly and Research Communication

Volume 4, Issue 3, Article ID 0301116, 5 pages

Journal URL: www.src-online.ca

Received February 13, 2013, Accepted March 17, 2013, Published November 30, 2013

Gaitán, Sol B. (2013). Children of the (Touch)screen: A Genesis. Scholarly and Research Communication, 4(3): 0301116, 5 pp.

(c) 2013 Sol B. Gaitán. This Open Access article is distributed under the terms of the Creative Commons Attribution Non-Commercial License (http://creativecommons.org/licenses/by-nc$\mathrm{nd} / 2.5 / \mathrm{ca}$ ), which permits unrestricted non-commercial use, distribution, and reproduction in any medium, provided the original work is properly cited.
Sol B. Gaitán is a teacher at The Dalton School, 108 E 89th St., New York, NY 10128. Email: solbia@earthlink.net . 


\section{Scholarly and Research}

\section{Communication}

VOLUME 4 / ISSUE 3 / 2013 games, and download information without being aware of the cognitive processes involved. Notions of technology such as CDs or DVDs are disappearing. As a seasoned teacher of children and adolescents, I have witnessed this transformation and I firmly believe that I have the moral obligation to prepare them for the world they will be part of as adults. I have been using technology in the classroom since 1993 and have witnessed rapid changes in students' attitudes toward technology, from its beginnings to their intuitive use of it today. Many of my adult peers, on the other hand, still tend to regard technology as a useful intruder that permits the uploading of grades or assignments and instant communication in the place of work or as a tool for shopping, an instant way to check the news, read periodicals and get directions. Many have become users of Facebook in their private life. Still, most educators are reluctant to explore ways of using technology for teaching, beyond applications many times imposed upon them by their institutions, such as Blackboard or electronic books. Some use blogs and wikis, but other networked applications are usually the realm of those who grew-up in the last decades.

More than 30 years have passed since Nam June Paik coined the terms "Electronic Super Highway" and "the future is now." Notwithstanding, our educational system continues to impose schedules devised during the Industrial era, a time when it was expected that most students would work in the factory line. We live and teach in a very different moment - a moment we should embrace with the understanding that it is in constant flux. As Sebastian Mary, a young British writer puts it: "many of us live now in a networked, post-industrial era, where many of the things that seemed so certain to a Dickens or Trollope no longer seem as reliable. And, perhaps fittingly, we have a new delivery mechanism for content. But unlike the book, which is bounded, fixed, authored, the Web is boundless, mutable, multi-authored and deeply unreliable" (Mary, 2007, para. 7).

This is precisely what I find so exciting about using technology, but also what makes me extremely careful. Computers are not a substitute for books, and smartboards are not a substitute for blackboards: they serve very different purposes. I have come to this realization throughout the many years I have used technology, both in and outside of the classroom. I will never substitute out pencil and paper for a computer, but I will always take advantage of what technology has to offer that cannot be replicated by other means. With that in mind, over the years I have created multiple e-assignments for my classes at the Dalton School in New York City, from Spanish I in the middle school to Hispanic Literature in the high school, a course in which the students produced e-books.

Because I was an early adopter of these technologies, the story I have to tell illustrates how people, in this case our future adults, experience information as readers and writers. I have evolved with technology, from the first application of hyperlinks before the commercialization of the Internet, to the use of social media as a tool for reading and writing in a formal literature class.

In 1993, I used Hypermedia Navigator, software developed at Dalton, which relied heavily on Hypercard and the notion of hyperlinks. I wanted my students to have access to text and media information with a mouse click. It was a painful, long process 
of digitizing text, music, and images and turning them into hypercards, in a world where digital searching tools did not yet exist. The final product was an electronic annotated edition of Federico García Lorca's Poema del cante jondo (1921), perhaps the most musical book there is, which allowed my students to actually hear the music inside that beautiful book. Back then, they approached this book with curiosity, albeit tentatively. After that experiment, however, they wondered about the other ways in which that book could ever be read. That was a triumph of technology use for serious reading. Some years later, I "transferred" that book into TK 3 , a new authoring/reading environment created by software publisher Night Kitchen, which allowed me to recreate Poema del cante jondo without any programming on my part, and with the addition of rich media. As technology continued to advance, in 2008, I used Sophie, a multimedia authoring program created by the Institute for the Future of the Book, which was designed by the same IT team behind $\mathrm{TK}_{3}$, to bring my edition of Poema del cante jondo to the present. Sophie included time-based events, and offered the possibility of integrating social networking into the experience of "reading" the book. The experiment was not completely satisfactory with respect to the interaction I expected among my students because they found the software difficult to use and because, in hindsight, social networking was not as prevalent in their lives as it is today. However, the new version of the book was beautiful and inspiring, and much better than the two previous ones.

Over the years, my goal in applying various technologies to this book has been to introduce my students to one of the most beautiful poetry collections regarding music in relationship to the peoples who produced it, in this case, the peoples of Andalucía. Thanks to Sophie, my students could explore the direct influence of the different music styles that comprise cante jondo on García Lorca's poetry. They also were provided with the tools to annotate several sections of the book. Sharing with the class proved quite difficult due to the issues that arise from using software that is in the Beta stage. I made the decision to pioneer this software with my class, because after having created the first version of an e-book in the most painful way (especially since I am not an IT person), no other product offered me what Sophie did. Unfortunately, Sophie has not advanced at the pace needed for my class, but I still hope for its future.

After that intent and without the promise that Sophie's social component offered, I adopted CommentPress. CommentPress was originally developed by Eddie Tejeda at the Institute for the Future of the Book, as an open source theme for the WordPress blogging engine that allows readers to comment paragraph by paragraph in the margins of a text, turning a document into a conversation. CommentPress is different from blogs or e-books because it provides a dynamic reading environment, where a piece of text can be annotated, as marginalia, or can be commented on by its readers by means of notes next to the text. Blogs support linear conversation, but CommentPress allowed readers to pull out multiple strands of text to start their own discussions. I used it with fixed documents. I have written assignments on many Spanish and Latin American authors using CommentPress. One of them was on Gabriel García Márquez's collection of short stories Los funerales de la Mamá Grande (1962) and his novella, El coronel no tiene quien le escriba (1961). We used both printed books and CommentPress, as students still wanted to hold a book in their hands. I wrote an essay using primary and secondary sources to illustrate how the evolution of the history of

Gaitán, Sol B. (2013). Children of the (Touch)screen: A Genesis. Scholarly and Research Communication, 4(3): 0301116, 5 pp.
VOLUMe 4 / ISSUE 3 / 2013 


\section{Scholarly and Research}

\section{Communication}

VOLUME 4 / ISSUE 3 / 2013
Colombia is at the core of García Márquez’s development as an author. I asked the class to comment on that essay based on what they had learned after reading his short stories. I also added a section of guiding questions, and a section with excerpts from the collection. My expectation was that the students would post comments to my text, but they seemed to prefer to go to the guiding questions and comment there. I believe they felt more comfortable with a familiar format of question/answer. After the class read El coronel no tiene quien le escriba, I asked them to enter comments to my essay as the culmination of the project. CommentPress allowed me to evaluate their work within the context of their whole experience and as they developed knowledge and understanding, something that a final paper does not necessarily do. Furthermore, the posting of comments helped students to know where they stood regarding assessment, because I used their posts in lieu of in-class essays. This rendered the evaluation process transparent since students were in intimate contact not only with their individual progress, but also with that of the whole class.

I valued enormously the fact that CommentPress extended the classroom beyond its physical confines. Because class discussions are central to Dalton's philosophy, students are quite accustomed to participating in class, so a student argued that she already shared her thoughts in class, and that she preferred to work on a paper in the privacy of her home rather than on a blog. Her argument was disputed by others who saw great learning advantages in the possibility of pondering the works of an author while they were reading at home and having the chance to share their ideas with their classmates, and with me, then and there. However, there was never a dialogue. They posted their thoughts as individual students, more like fulfilling a class requirement.

I jumped at the opportunity to try a new approach to reading when Bob Stein, the instigator behind most of my experiments using technology, presented SocialBook to me. SocialBook places great importance on the social networking aspect of a blog, but avoids the verticality of blogging by providing a more expansive and immediate conversation within the book. This software is in development, and my class and I were very excited to be part of this experiment. Through Bob Stein, we were in constant contact with the IT developers (Astea Solutions) in Sofia, Bulgaria, who paid great attention to our feedback. We used SocialBook to read large portions of the two parts of Don Quijote de la Mancha, Miguel de Cervantes Saavedra (Vol 1, 1605/Vol 2, 1615). I loved the fact that we were reading the book that changed forever the way humanity writes, using software that may change forever the way humanity reads. The icing on the cake, as a teacher and early adopter, was to witness the nature and quality of the conversation that went on. Students were addressing each other by name, creating amazingly interesting threads, quoting from different parts of the book and from each other's comments, and linking to some obscure medieval texts to illustrate and support their arguments. In all the years I have been using technology, this time I felt on par with my students and their times. This year the experiment has been even more rewarding. The quality of class discussions has ascended to a level that I had never experienced before. Students have become intimate with the texts they are reading in a unique way because they are doing a closer reading than when they read a paper book, since they are sharing their thoughts with the class. The unique thing is that they are truly interacting with each other while reading, highlighting segments that can vary from a sentence or a verse in a poem, to a paragraph, which was not the case with blogs. 
As a result, they bring that experience to the classroom and our discussions revolve around an ongoing conversation that takes the class home and home to the class in a seamless way. Homework has then taken on a lovely hue because we use it as the pivot of our class.

One argument I have used with those students who expressed uneasiness at using a networked assignment is that we are using their favourite tool for communication. They all agree that social networking, text messaging, and some email, are the way they connect. Why then, do they object to having this applied to their learning experience? There is a feeling that an academic blog demands a "serious" approach and a certain degree of formality, and students also feel that they must comment. With SocialBook we decided to follow a less formal, though no less rigorous, approach to a text. We also decided to enter a minimum of comments per assigned reading, since they write in Spanish, which does not come to them with the same degree of easiness and freedom as English. What I find fascinating is that the medium has conquered them. Without realizing it, they follow their natural urge to share their opinions with their friends without counting how many times they post a comment. This has made their Spanish more fluent and relaxed, while their level of discourse is extremely sophisticated both in class and on SocialBook. And all of this is happening in an organic way. What else could a teacher hope for?

\section{Reference}

Mary, S. (2007). It's a multimedia, Jim, but not as we know it. if:book. URL: http://www.futureof thebook.org/blog/archives/2007/04/its_multimedia_jim_but_not_as.html [April 12, 2013].
Scholarly and Research

Communication

VOLUME 4 / ISSUE 3 / 2013 